\title{
Regional Convergence Clusters across Europe
}

\author{
by \\ Danny T. Quah* \\ LSE Economics Department and CEP \\ CENTRE FOR ECONOMIC PERFORMANCE \\ DISCUSSION PAPER NO. 274 \\ December 1995
}

This paper is produced as part of the Centre's Programme on National Economic Performance.

* I thank Ana Lamo for early help with the data. The calculations here were done using a combination of lisp, perl, and tSrF. The European Commission kindly provided maps and other information. 


\section{Nontechnical Summary}

GDP will become increasingly weightless as economies grow progressively knowledge- and information-based. A succinct term for this is "dematerialization." With increasing dematerialization, traditional economic mechanisms of gradual dynamic adjustment and spatial spillovers could well become irrelevant, at the same time that the nation-state withers in importance.

This view derives from two distinct arguments. First, as bandwidth increases without bound for transporting economic value across space, the importance of physical distance, slow adjustment, and spatial agglomeration benefits must correspondingly decrease. Second, when economic value no longer needs to take any physical manifestation (whether that value subsequently is in the form of electronic accounts on a clearing system, of information content in electronic broadcasts, or of ideas and design encapsulated in software), nation-states will have progressively fewer ways of controlling or even defining that which is particular to individual nations.

This paper seeks to provide a first step in quantifying the importance of nation-state and spatial-spillover factors on economic well-being across regions in Europe. For this analysis, the paper uses an empirical model of dynamic (cross-region, income) distributions. Technically, the paper seeks characterizations of a sequence of distributions in terms of their ergodic and convergence behavior; the current work improves on earlier related investigations in applying a conditioning operation to the distribution dynamics - the conditioning is one that is naturally suggested by the issues being studied here.

The paper asks how close, in their economic performance, European regions are to being like isolated islands. As the empirical technique makes clear, what is of concern here is not whether there is strong correlation across regions, whether there are common factors underlying regional fluctuations, or whether dynamics are "similar" or "common" across regions. Instead, this paper looks at the dynamic implications for 
convergence - poorer regions catching up with richer ones - of the dematerialization scenario described above. Given actual historical developments, are regions across Europe clustering into centers of agglomeration? Or, instead, are patterns of economic well-being levelling out to be equitable across physical geography? In carrying out this investigation, the paper ends up providing a detailed picture of the dynamics of spatial and national income distributions across Europe. Such empirical analysis aids our understanding of the convergence and cohesion possibilities of locally-focused and macroeconomic policies; it is thus useful regardless of whether one thinks important the dematerialization and "knowledgebased economy" concerns outlined above.

The empirical model of distribution dynamics used below draws on related work elsewhere that has focused on cross-country growth and convergence. This body of work eschews standard regression methods as the latter average across observations to construct only a (conditional) average: but knowing how an average behaves reveals nothing about the relative behavior of rich and poor parts of the cross section distribution. For that, one needs an explicit model of distribution dynamics. The analysis in this paper uses exactly that. Additionally, in the application to European regions here, the work needs to take into account the geographical (i.e., physical) location characteristics and nation-state identification of different parts of the cross-section distribution. The paper provides a technique for exploiting this conditioning information in a model of explicit distribution dynamics.

This paper, then, finds that spatial-spillover factors matter more than do national, macro ones. Both, however, have been important historically. One interpretation of these findings is that the dematerialization concerns above are empirically irrelevant. The other interpretation is that those forces have not yet come into play and that what has been estimated here simply calibrates the magnitudes of changes to come. 


\title{
Regional Convergence Clusters across Europe \\ by \\ Danny T. Quah \\ LSE Economics Department and CEP \\ December 1995
}

\begin{abstract}
Per capita incomes across European regions are not equal and do not stay constant; regional income distributions fluctuate over time. Such a process could have many possible limiting outcomes: complete equality (convergence), stratification, and continually increasing inequality are but three distinct possibilities. This paper asks if nation-state, macro factors and physical-geography spillover effects help explain the observed distribution dynamics across European regions. Geographical factors are found to matter more than national ones; but both are important for explaining inequality dynamics.
\end{abstract}

Keywords: conditioning, dematerialization, distribution dynamics, economic geography, knowledge-based economy, location

JEL Classification: C22, C23, D30, D63, O30, O57

Communications to: D. T. Quah, LSE, Houghton Street, London WC2A 2AE.

[Tel: +44-171-955-7535, Fax: +44-171-831-1840, Email: dquah@1se.ac.uk] 



\section{Introduction}

Location and physical geography are irrelevances in the economies constructed by Gibson (1984), Stephenson (1992), and Sterling (1988). Sure, there is urban sprawl-millions continue to live in recognizable counterparts to Greater London, Tokyo, New York, and Mexico City - but, in those made-up, artificial economies, wealth creation occurs in disembodied, dematerialized processes. Little that is physical is worth much. Or, more correctly, all things that are economically valuable - database information, gene sequences, computer software, encryption and code-cracking algorithms - retain value independent of their physical manifestation. In producing and consuming GDP, nothing material needs to move from one place to the next. GDP is weightless; communication costs are zero; transporting economic value anywhere is instantaneous. Whatever agglomeration externalities might exist, none could be spatially concentrated.

Of course, actual economies don't behave like that. In reality, location matters: consumption and output remain mostly of physical stuff; and, (economists think) people continue to share ideas and insights better when working close to each other.

But, the vision described in the first paragraph is not completely unfounded, even in present reality. Manufacture of the world's most valuable commodity already takes a form that is location-blind: ${ }^{1}$

"Texas Instruments' high-speed telecommunications chip may look like any other semiconductor: But it's the product of a world's worth of effort. Conceived with engineers from Ericsson Telephone Co. in Sweden, it was designed in Nice with software tools the company developed in Houston. Today, the TCM9055 chip rolls off production lines in Japan and Dallas, gets tested in Taiwan, and is wired into Ericsson line-cards that monitor phone systems in Sweden, the U.S., Mexico, and Australia."

And, contrary to many economists' thinking, physical geography is irrelevant for

1 “The Global Chip Payoff," Business Week, 7 August 1995. 
intellectual collaboration in many successful research enterprises: ${ }^{2}$

"A networked corporation can do business anywhere, anytime, getting a jump on competitors that still conduct business the old-fashioned way. And it no longer matters where your best and brightest talent resides: Sweden's L. M. Ericsson has 17,000 engineers in 40 research centers located in 20 countries around the world, all linked into one network. Development teams in Australia and England work together on the same design, then zip off the final blueprint to a factory in China."

If anything, economists who study physical-location externalities seem to be concentrating on those old-fashioned businesses that, according to this quote, are constantly being jumped. Moreover, modern managers and research scientists explicitly recognize and welcome this physical dislocation: ${ }^{3}$

"While increasing numbers of workers will need ready access to wideranging information resources, optimal information sharing needn't demand one's physical presence in some corporate office complex. Tomorrow's interactions may depend far more on shared understanding than on sharing the same office corridor."

For brevity, I will refer to the above circle of ideas as relating to the knowledgebased economy.

This emphasis on dematerialization in information and communication is not confined to hi-tech, profit-seeking, private economic agents. The World Bank sees the knowledge-based economy, founded on information networking, as a "dramatic opportunity [for Sub-Saharan Africa] to leapfrog into the future, breaking out of decades of stagnation or decline." 4

2 "The Networked Corporation," Business Week, 26 June 1995. The Ericsson in this example is the same as that in the previous.

3 Arno Penzias, Harmony, excerpted in Fortune, 12 June 1995.

${ }^{4}$ URL : http : / www . worldbank .org/html/emc/Welcome .html "Increasing Internet Connectivity in Sub-Saharan Africa" (accessed, August 1995). 
Such knowledge-based economy views can have profound implications. Under the natural interpretation, physical location and the host sovereign country are irrelevant for where economic activity happens. ${ }^{5}$ Geographical regions, if they remain meaningfully defined, would be like isolated islands: neither their being part of a country, nor their being physically close to another region makes any difference for their economic performance.

Below, I use this extreme "knowledge-based economy" view as a strawman, backdrop hypothesis for studying the distribution dynamics of regional incomes across Europe. Holding up such an empirical study to this extreme view is unfair to the latter: this view has implications that are subtle, and not yet completely in place. However, performing the study thus allows us to quantify the existing economic-geography features that, in this view, are targeted for change. Also, taking such a perspective allows us to abstract away from specific details of models of geography and location, and to clarify the macro issues at stake. Finally, what empirical evidence can be adduced adds to understanding: more than informal anecdote is needed to gauge the extreme view's relevance. The examples mentioned above can easily be matched by others that argue the opposite.

Thus, this paper asks, How close are European regions to isolated islands? How much does knowing the host country's economic performance help explain the region's? How much does knowing that of surrounding regions - which, of course, might belong to different host countries - help explain the region's? How much do these help explain the dynamics of regional income distributions? The answers to these questions, in the extreme view, are "completely" for the first, and "not at all" for all the remainder.

By contrast, in the empirics below, I show that a region's economic well-being can be predicted by that in both surrounding regions and the host state. Both factors matter for regional distribution dynamics. Thus, by either consideration,

5 Angell (1995) and Ohmae (1995) argue a more detailed case for the nation state's eventual irrelevance, based on considerations similar to those I have just described. 
European regions are not isolated islands.

More than does the host country's economic performance, that of surrounding regions helps us understand the inequalities across European regions. Thus, for explaining regional distribution dynamics, physical location and geographical spillovers matter more than do national, macro factors.

\section{Empirics}

European regions - as do all geographical units - spread out on a two-dimensional map; the economic performance of each region can be represented as a height above that map. Connecting those heights across space, the result is a mathematical surface over the physical geography of Europe. Then, regional distribution dynamics are vibrations in this surface.

In studying such dynamics, the researcher seeks to quantify spillover and interaction across regions; he seeks to understand the dynamics of the entire crosssection distribution. No region is representative; no region can be studied in isolation independently of others. Thus, regression-based approaches, averaging across either cross-section or time-series dimensions, are not useful. Such methods construct a (conditional) representative, and cannot provide a picture of how the entire cross-section distribution evolves. ${ }^{6}$

While the description given in the first paragraph of this section is conceptually clean, data limitations prevent its empirical implementation. Instead, I use an alternative but still explicit model of distribution dynamics.

6 This point is forcefully made in Quah (1996b). Dobkins and Ioannides (1995), Eckstein and Eaton (1994), and Larch (1994) have also recognized this, and use methods related to those below in their empirical analyses. Spatial processes, e.g., Cliff and Ord (1981), provide useful associated tools, although emphasis there has primarily been on variation only across space, and not simultaneously over time. See, however, Roehner (1993), which does consider spatial and dynamic correlations jointly. 
Figure 1 shows, for different time periods, the density of the (log of) regional per capita income distribution, relative to the European average. Panel (a) shows the density for 1980-1982; (b), for 1983-1985; (c), for 1986-1988; and finally, (d), for 1989 alone. $^{7}$

Two features of this sequence of distributions concern us: first, churning or intra-distribution dynamics, not shown in Figure 1; and second, changes in the external shape of the distributions. Take these in reverse order. The dynamic sequence in Figure 1 suggests a reduction, over time, in the cross-sectional spread of relative incomes. Indeed, the standard deviation starts at 0.274 in 1980 , increases to a peak of 0.284 in 1981, and then falls monotonically to 0.251 in 1989 : this is an $8 \%$ decline over 10 years. Next, a first-order Markov chain fit to this distribution sequence, discretized into 5 equal-proportioned cells over the observed sample, gives an ergodic limit that is unimodal about the mean. ${ }^{8}$ In words, the regional income distribution is converging towards a tighter, more concentrated distribution than exists on average in the sample. Moreover, in the estimated Markov chain, transition probabilities out of the current state average 10\%: thus, there is also substantial intra-distribution churning. Over time, poor regions are becoming richer, and vice versa.

Under the extreme "knowledge-based economy" view of the previous section,

7 To meet space restrictions, Figures 1-3 are not in the published version of this paper, but may be found in the Working Paper preprint. I use Eurostat's (1992) purchasing-power standardized per capita incomes; details on this and other data issues appear in the Appendix (similarly, in the Working Paper preprint, but unavailable in the published version). All subsequent data are on log relative incomes; I will drop the "log" for brevity. The densities in Figure 1 were estimated by Gaussian kernel smoothing, using bandwidths given in Silverman $(1986,3.4 .2)$.

8 The defining grid points selected by the data are at $73.5 \%, 88.0 \%, 100.0 \%$, and $115.6 \%$. To save space, details on this procedure cannot be given here, but the reader can see similar applications to distribution dynamics in Quah (1993a, 1993b, 1994, 1996a) and elsewhere. 
the distribution dynamics just described should be unaffected by conditioning on host nation-state or neighboring-region information. To assess this, I constructed two more relative income series: first, state-relative income, where I normalized each region's per-capita income by the per-capita income in the host nation-state, excluding the region itself; and second, neighbor-relative income, where I normalized each region's per-capita income by the average per-capita income of the surrounding, physically contiguous regions. It is convenient to think of these two relative incomes as the parts unexplained by nation-state factors and physicallocation factors, respectively. ${ }^{9}$ If the host nation-state or physical location explains everything, what is left over vanishes, or is small. If, on the other hand, the extreme-view backdrop hypothesis holds, what is left over is what we begin with.

Figures 2 and 3 are counterparts to Figure 1 for state-relative and neighborrelative incomes, respectively - the scale for all three figures is the same to ease comparison. The first conclusion from studying these is that the neighbor-relative distributions in Figure 3 are tighter and more concentrated than those of either Europe-relative or state-relative incomes. The neighbor-relative distribution has standard deviation 0.212 in 1980 , increases to a peak of 0.227 in 1984, and then falls monotonically to 0.181 in 1989 . The decline over 10 years is $15 \%$. Comparing 1989 standard deviations, neighbor-conditioning gives a reduction of $28 \%$ over that in Europe-relative incomes. By contrast, the state-relative distribution has standard deviation 0.222 in 1980 , increases to a peak of 0.234 in 1981, and then falls to 0.218

${ }^{9}$ Of the 78 regions in the sample, 13 had neighboring regions in countries other than the region's own host itself; 6 had no neighboring regions at all. The average number of physical-neighbor regions was 3.3; the average number of host-nation regions was 13.5. More refined conditioning is certainly possible: one might want to take into account (i) relative sizes measured by area, say; (ii) physical lengths of abutting boundaries; or even (iii) the physical characteristics of the border terrain. Also, instead of just taking relative per capita incomes, more flexible measures of unexplained components might be calculated. Such extensions, however, cannot be treated within the restricted scope of the current paper. 
in 1989. Here, the decline over 10 years is $2 \%$. Comparing standard deviations in 1989, state-conditioning gives a reduction of only $13 \%$ over that in Europe-relative incomes.

But more information is available: Tables 1 and 2 show transition probabilities across pre- and post-conditioned income distributions. If conditioning explained nothing - our extreme strawman hypothesis - these transition probability matrices should be the identity matrix: the distributions are invariant, and, in addition, no intra-distribution movements occurs. The reality, however, is different. For instance, in Table 1, the top left-hand entry shows that the poorest $20 \%$ of European regions - having incomes less than $74 \%$ of the average - remained with incomes in that range only with probability 0.49 , after conditioning on their fellow regions in the host nation-state. The corresponding entry in Table 2 shows even greater change: there, the probability of remaining in the same income range is only 0.2 , after conditioning on physically-contiguous regions.

Every diagonal entry in Table 2 is smaller than the smallest diagonal entry in Table 1: conditioning on physically-contiguous regions accounts for more observed regional inequality than does conditioning on nation-state information. Diagonal entries in Table 1 average to 0.6: conditioning on nation-state information already accounts for a substantial amount of observed regional inequality. Those in Table 2 average to only 0.3 : neighboring-region information accounts for even more.

\section{Conclusion}

This paper has taken as its underlying, backdrop hypothesis an extreme caricature of the irrelevance of economic geography. The paper finds, according to its dynamic-distribution measures, that physical location and geographical spillover matter more than do macro factors. Both sets of factors account for a substantial amount of the regional income distribution dynamics. There is thus strong evidence against our strawman hypothesis. However, the empirical results here carry interest, regardless of whether one takes seriously that hypothesis: the re-

sults highlight the importance of spatial and national spillovers in understanding 
regional income distribution dynamics. ${ }^{10}$

As intended, the paper also carries interest more generally for dynamic geographical and spatial analyses. Methodologically, the paper provides an empirical framework to study the predictions of models such as in Krugman and Venables (1995). The conditioning analysis in Tables 1 and 2 differs from that in Quah (1996b); it extends easily to allow richer study of conditioning in models of distribution dynamics.

10 One should be circumspect in whether to dismiss casually the strawman hypothesis. The findings here do not say that the "knowledge-based economy" factors described above are irrelevant. One can, instead, interpret these findings as simply quantifying the changes that could occur when the dematerialized, knowledgebased economy comes online. Explicit economic models remain to be worked out, supporting empirical investigations remain to be done, but this author's instincts are that some version of the knowledge-based economy scenario described in the Introduction is not far in the future. Informal but detailed arguments are laid out in Angell (1995) and Ohmae (1995); Quah (1995) contains a tentative theoretical analysis. 


\section{References}

Angell, Ian (1995) "Goodbye to nation, hello the world," UK Parliamentary Brief pp. 39-40, May

Cliff, A. D., and J. K. Ord (1981) Spatial Processes: Models and Applications (Pion Limited)

Dobkins, Linda Harris, and Yannis M. Ioannides (1995) "Evolution of the U.S. city size distribution," Working Paper, Economics Department, Tufts University, July

Eckstein, Zvi, and Jonathan Eaton (1994) "Cities and growth: Theory and evidence from France and Japan," Working Paper, Economics Department, TelAviv University, September

Eurostat (1992) REGIO Regional Data Bank (Brussels: European Commission)

Gibson, William (1984) Neuromancer (Ace Books)

Krugman, Paul, and Anthony J. Venables (1995) "The seamless world: A spatial model of international specialization," Working Paper, Economics Department, LSE, July

Larch, Martin (1994) "Regional cross-section growth dynamics in the European Community," Working Paper, European Institute, LSE, London, June

Neven, Damien J., and Claudine Gouyette (1994) "Regional convergence in the European Community," Discussion Paper 914, CEPR, London, February

Ohmae, Kenichi (1995) The End of The Nation State: The Rise of Regional Economies (New York: The Free Press)

Quah, Danny (1993a) "Empirical cross-section dynamics in economic growth," European Economic Review 37(2/3), 426-434, April

(1993b) "Galton's fallacy and tests of the convergence hypothesis," The Scandinavian Journal of Economics 95(4), 427-443, December 
(1994) "One business cycle and one trend from (many,) many disaggregates," European Economic Review 38(3/4), 605-613, April

(1995) "Ideas determining convergence clubs," Working Paper, Economics Department, LSE, London, August

(1996a) "Aggregate and regional disaggregate fluctuations," Empirical Economics. Forthcoming

(1996b) "Convergence empirics across economies with (some) capital mobility," Journal of Economic Growth. Forthcoming

Roehner, Bertrand M. (1993) "Trade and space-time correlation functions in dynamic random field models," Working Paper, Laboratoire de Physique Theorique et Hautes Energies, Université Paris

Silverman, Bernard W. (1986) Density Estimation for Statistics and Data Analysis (New York NY 10001: Chapman and Hall)

Stephenson, Neal (1992) Snow Crash (Bantam)

Sterling, Bruce (1988) Islands in the Net (Arbor House) 
Table 1: State-relative per capita incomes*

\begin{tabular}{|l|ccccc|}
\hline \hline (Number) & 0.74 & 0.88 & 1.00 & 1.16 & $\infty$ \\
\hline$(125)$ & 0.49 & 0.20 & 0.23 & 0.08 & \\
$(128)$ & 0.09 & 0.49 & 0.06 & 0.14 & 0.22 \\
$(121)$ & & 0.17 & 0.68 & 0.01 & 0.14 \\
$(129)$ & & 0.09 & 0.38 & 0.46 & 0.07 \\
$(121)$ & & & 0.02 & 0.31 & 0.66 \\
\hline \hline
\end{tabular}

Table 2: Neighbor-relative per capita incomes*

\begin{tabular}{|l|ccccc|}
\hline \hline (Number) & 0.74 & 0.88 & 1.00 & 1.16 & $\infty$ \\
\hline$(125)$ & 0.20 & 0.26 & 0.31 & 0.16 & 0.06 \\
$(128)$ & 0.09 & 0.38 & 0.20 & 0.21 & 0.13 \\
$(121)$ & & 0.40 & 0.38 & 0.19 & 0.03 \\
$(129)$ & & 0.18 & 0.40 & 0.29 & 0.13 \\
$(121)$ & & & 0.18 & 0.37 & 0.45 \\
\hline
\end{tabular}

* These transition probabilities describe transitions from Europe-relative incomes to state-relative and neighbor-relative incomes, respectively. They thus quantify the effects of conditioning, and not transitions over time. The grid is empirically chosen as described in footnote 8. Cells are arrayed in increasing order, with the lower right-hand corner displaying transitions from rich to rich; cell entries that are zero to two decimal places are omitted. The numbers in parentheses on the left are the number of region/year pairs beginning in a particular cell. 


\section{Appendix}

The data are from Eurostat (1992). As does the rest of the European Commission, Eurostat uses the agreed-upon nomenclature of statistical territorial units referred to as NUTS (pronounced as spelt).

These territorial units partition into successive, strict refinements: thus, any NUTS-1 territorial unit contains an integral number of NUTS-2 units each of which, in turn, contains an integral number of NUTS-3 units, and so on. In 1992, the European Community contained 71 NUTS-1 units, 183 NUTS-2 units, and 1044 NUTS-3 units. These included the French Overseas Departments-French Guyana in South America, and the small islands Guadeloupe, Martinique (50+ degrees West, in the Caribbean), and Reunion (50+ degrees East, by Mauritius and Madagascar, in the Indian Ocean); the Canary Islands in the Atlantic off Morocco and Western Sahara; and Ceuta and Melilla (two small towns in north Africa, on the Mediterranean coast). Readers interested in more detail will find immeasurably useful the maps provided by the Commission.

To get a rough idea of the degree of regional disintegration analyzed in the text, it is useful to note some further NUTS facts. In 1992 Commission terminology, NUTS-1 units were also called European Community Regions; NUTS-2 units, Basic Administrative Units; and NUTS-3 units, Subdivisions of Basic Administrative Units. (There are even data at NUTS-4 level becoming available.) Within each member state, however, terminology differed. France, Italy, and Greece referred to NUTS-2 units as regions. By contrast the UK called NUTS-1 units regionsconsistent with Commission usage - while Ireland called its NUTS-3 units regions.

The UK has no official counterpart to NUTS-2 units; its 35 Basic Administrative Units were drawn up only for Commission use as groups of counties. Then, into the UK's 65 NUTS-3 units fell a combination of counties and local authority regions - two concepts that UK local government administration keeps distinct. As with the UK's NUTS-2 units, NUTS-1 regions in Greece and Italy were defined only for Commission use.

Belgium and the Netherlands called NUTS-2 units provinces, while Italy and 
Spain kept that name for their NUTS-3 units. In Eurostat accounting, Ceuta and Melilla comprise a single Spanish NUTS-2 unit, while Spain considers neither (one nor both) Comunidades autonomas, its terminology for all of its other NUTS-2 units.

I take the basic data to be the purchasing-power standardized per capita incomes in regions [series ECON2PIB measured in PPS_HAB units], from 1980 through 1989. The usable series are then:

\begin{tabular}{|c|c|}
\hline Belgium & $\begin{array}{l}\text { Antwerpen, Brabant, Hainaut, Liege, Limburg (Bel- } \\
\text { gium), Luxembourg (Belgium), Namur, OoostVlaan- } \\
\text { deren. WestVlaanderen }\end{array}$ \\
\hline Germany & $\begin{array}{l}\text { Baden-Württemberg, Bayern, West Berlin, Bremen, } \\
\text { Hamburg, Hessen, Niedersachsen, Nordrhein-Westfalen, } \\
\text { Rheinland-Pfalz, Saarland, Schleswig-Holstein }\end{array}$ \\
\hline Spain & $\begin{array}{l}\text { Galicia, Asturias, Cantabria, Pais Vasco, Navarra, } \\
\text { Rioja, Aragon, Madrid, Castilla-Leon, Castilla-La Man- } \\
\text { cha, Extremadura, Cataluna, Comunidad Valenciana, } \\
\text { Baleares, Andalucia, Murcia, Ceuta y Melilla, Ca- } \\
\text { narias }\end{array}$ \\
\hline Italy & $\begin{array}{l}\text { Piemonte, Valle D'Aosta, Liguria, Lombardia, Trentino- } \\
\text { Alto Adige, Veneto, Friuli-Venezia Giulia, Emilia- } \\
\text { Romagna, Toscana, Umbria, Marche, Lazio, Cam- } \\
\text { pania, Abruzzi, Molise, Puglia, Basilicata, Calabria, } \\
\text { Sicilia, Sardegna }\end{array}$ \\
\hline Netherlands & $\begin{array}{l}\text { Groningen, Friesland, Drenthe, Utrecht, Noord-Holland, } \\
\text { Zuid-Holland, Zeeland, Noord-Brabant, Limburg (Nether- } \\
\text { lands) }\end{array}$ \\
\hline United Kingdom & $\begin{array}{l}\text { North, Yorkshire and Humberside, East Midlands, } \\
\text { East Anglia, South East, South West, West Mid- } \\
\text { lands, North West, Wales, Scotland, Northern Ire- } \\
\text { land }\end{array}$ \\
\hline
\end{tabular}

From these, three relative income series are constructed: first, per capita income relative to the European average; per capita income relative to other regions in the country; and, finally, per capita income relative to physically contiguous regions, or physical neighbors. For brevity, the text refers to these, respectively, 
as Europe-relative (or just relative), state-relative, and neighbor-relative.

Since I do not have data on all countries and regions, when I say European average, I mean the average for the sample that is used. Similarly, when data for physically contiguous regions are unavailable, I treat those regions as nonexistent. Thus, while islands such as Baleares, Canarias, Sicilia, and Sardegna necessarily have no neighbors, Berlin - which is land-locked - is also treated as physically isolated. Spanish Ceuta and Melilla, taken as one region, aren't even contiguous with each other, much less with anyone else in Europe.

Information on nation-state membership and physical contiguity was taken off paper maps, and coded into a lisp object. A perl program read the information there encoded, and wrote tSrF code, which then produced all the calculations and graphs in the paper.

As others, e.g., Neven and Gouyette (1994), have observed, Groningen in the Netherlands has its per capita GDP considerably increased by North Sea oil revenues. In the current study, however, the conclusions do not substantively change with or without Groningen. All the findings in the text thus include Groningen. 

Figure 1: Cross-region Relative Income, Densities

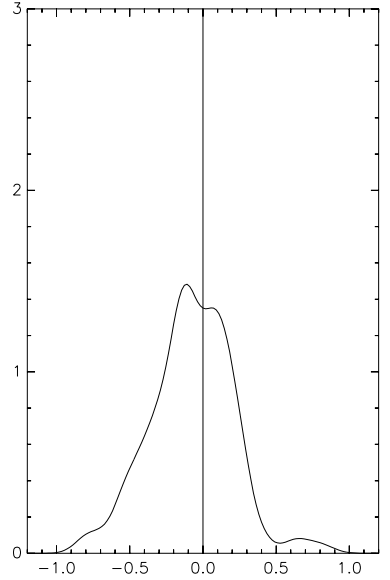

(a) 1980-82

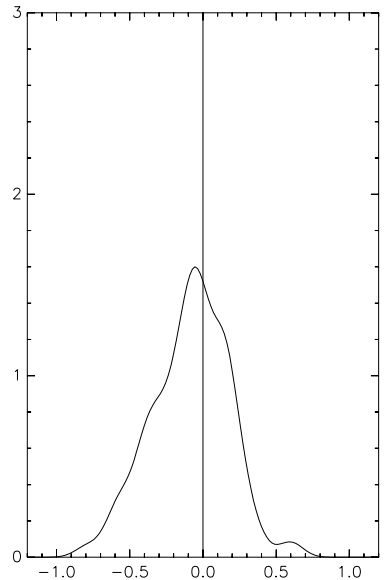

(c) $1986-88$

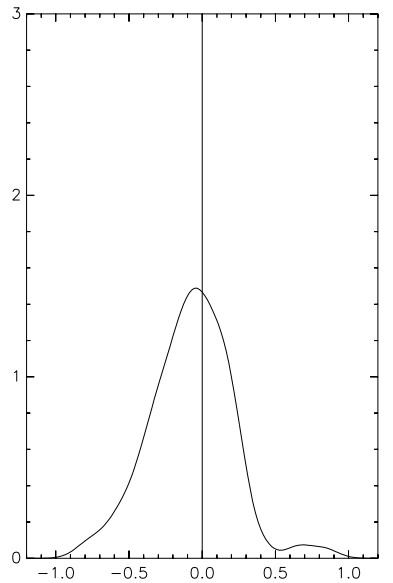

(b) 1983-85

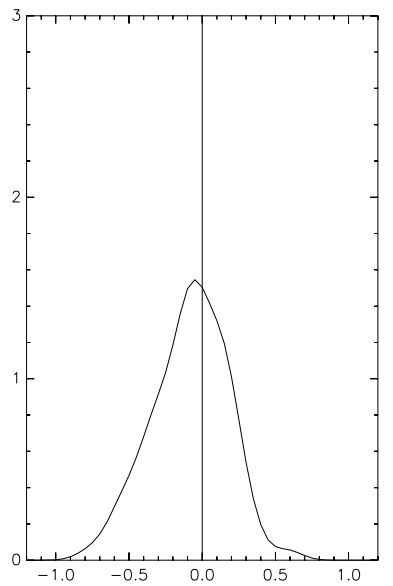

(d) 1989 
Figure 2: Cross-region (Nation-State) Relative Income, Densities

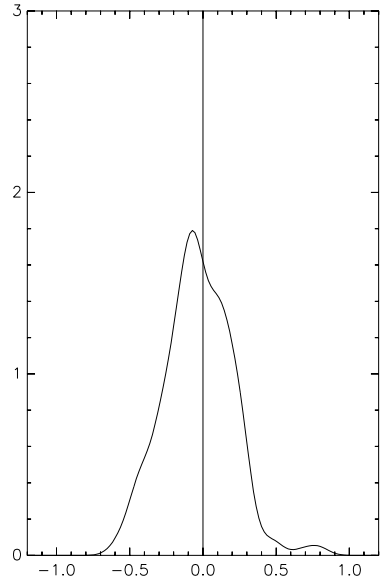

(a) 1980-82

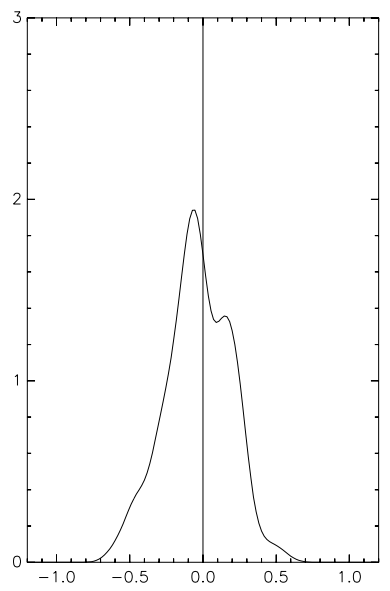

(c) 1986-88

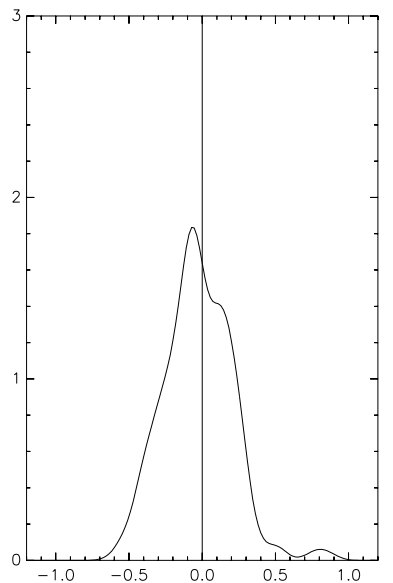

(b) 1983-85

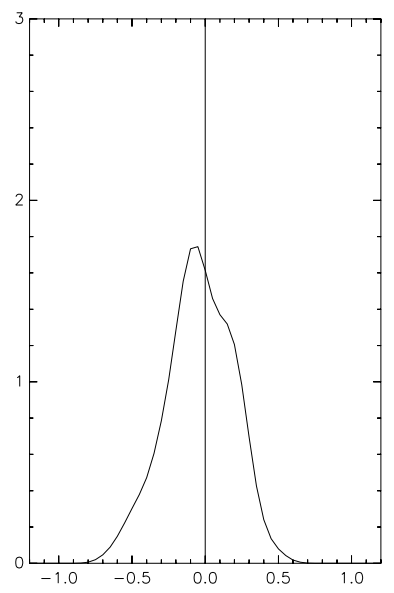

(d) 1989 
Figure 3: Cross-region (Physical-Neighbor) Relative Income, Densities

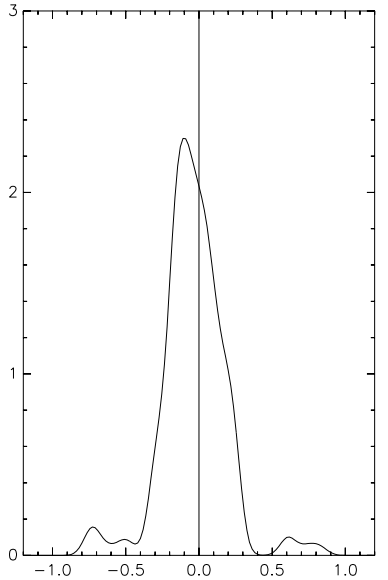

(a) 1980-82

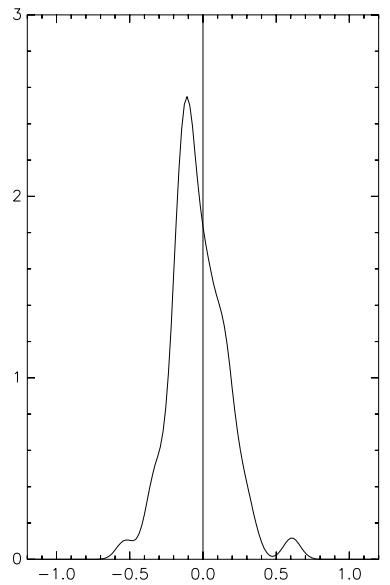

(c) $1986-88$

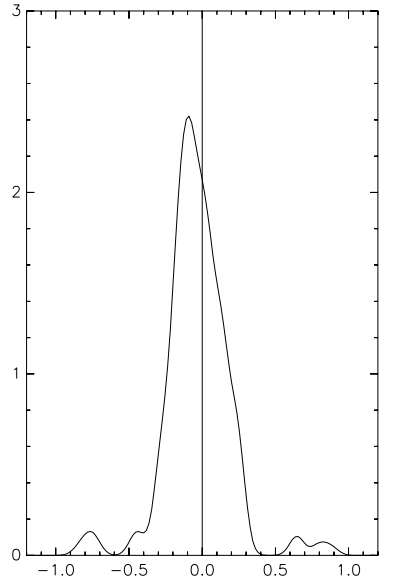

(b) 1983-85

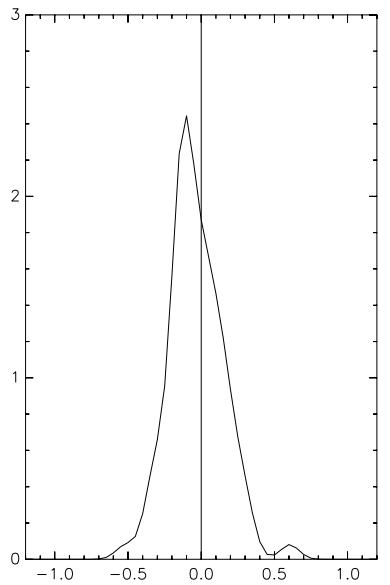

(d) 1989 